\title{
Are specialist outreach clinics for orthodontic consultation effective? A randomised controlled trial
}

\author{
K. O'Brien, ' R. Mattick, ${ }^{2}$ N. Mandall, ${ }^{3}$ J. Wright, ${ }^{4}$ F. Conboy, ${ }^{5}$ and T. Gosden, ${ }^{6}$
}

\begin{abstract}
Objective To develop outreach clinics for orthodontic consultation and evaluate their costs and effectiveness. Design Single centre randomised controlled trial with random allocation of referred patients to outreach or main base consultation appointments.

Setting One hospital orthodontic department and three community health centre clinics in Greater Manchester.

Subjects 324 patients who were referred for orthodontic treatment.

Main outcome measures The outcome of consultation, the cost and duration of the visit and the consumer's perceptions of the visit.

Results There were no differences in outcome of the consultation. While consumer travel costs and the duration of appointments were significantly higher for the main base clinics, these differences were not great. However, consumers preferred to attend an appointment in an outreach clinic.

Conclusions There do not appear to be marked advantages or disadvantages in providing consultation appointments for orthodontics in outreach clinics
\end{abstract}

Secondary dental care is provided through most district general Shospitals in the UK. Delivery of treatment is based around the traditional pattern of referral of prospective patients to the consultant's base hospital and further care is arranged, if necessary. Recently, in medicine and surgery, outreach clinics in which the hospital based specialist provides a consultation service in a primary care setting rather than the hospital have become increasingly common, mostly in general practitioner fundholding practices. ${ }^{1-3}$ The main aims of these developments are to increase consumer accessibility, reduce waiting times for appointments and increase interaction and feedback between the secondary and primary care providers. ${ }^{1,4}$

While these aims are laudable, research has revealed that these benefits do not always arise. For example, an investigation into ophthalmic specialty outreach revealed that patient access was improved and patients preferred attending the outreach clinic. Unfortunately, the cost of the outreach clinic was higher than the hospital clinic because the throughput of patients was less. ${ }^{5}$ Other, more recent research into outreach for orthopaedics and dermatology revealed that even though this type of provision of care was

${ }^{1}$ Professor, ${ }^{2}$ Senior Registrar, ${ }^{3}$ Lecturer/Honorary Senior Registrar, ${ }^{4}$ Research Associate, ${ }^{5}$ Research Associate, Department of Dental Medicine and Surgery, The University Dental Hospital of Manchester, Higher Cambridge Street, Manchester M15 6FH; ${ }^{6}$ Health Economist, National Centre for Primary Care Research,

Williamson Building, University of Manchester, Oxford Road, Manchester M13 9PL Correspondence to:Kevin O'Brien

email: Kevin.O’Brien@man.ac.uk

REFEREED PAPER

Received 21.11.00; Accepted 02.04.01

(c) British Dental Journal 2001; 191: 203-207 popular with primary care providers, there did not seem to be an increased level of interaction between general practitioners and specialists. ${ }^{6}$ When costs were considered, there was little difference between the two settings and when the patient's opinion on the site of the consultation was analysed it appeared that they were more concerned about actually seeing a specialist than the location of the clinic. $^{7}$ In contrast, another investigation of three other specialties found that patients were more satisfied and preferred the convenience of the outreach clinic. ${ }^{8}$ One drawback of these studies was that it was not possible to randomly allocate patients to either outreach or hospital based care. As a result, they could not control for different case mixes between the two settings.

While these latter findings may appear discouraging, the authors suggest that other specialities may be more suited to outreach clinics than those which they investigated. ${ }^{6,7}$ In this respect dentistry appears to be suitable because the necessary diagnostic facilities are available in most community clinics and large general dental practices and, importantly, there is not a wide case mix of conditions within each dental specialty. Secondly, the primary/secondary care interface in dentistry is characterised by long waiting lists and high levels of inappropriate referral. ${ }^{9,10}$ One solution to these problems may be the development of specialist outreach for dentistry. However, before changes are considered it is important to establish that benefits to both the providers and consumers arise from the change. This is the aim of our investigation.

We tested the following null hypotheses - There are no differences between the main base and outreach consultation service in terms of:

- Consumer's access to care

- Consumer's views of their care

- The outcome of consultation for patients

- The costs to consumers

We also determined NHS costs associated with each site.

\section{Methods}

\section{Protocol}

This study was based in the Manchester and West Pennine Health Authorities. These areas contain a population of 685,000. Primary dental care is provided by 365 general dental practitioners and 36 community dentists equating to 24.29 full time equivalents. One community orthodontist, 4 specialist orthodontic practitioners and 5 consultant orthodontists provide secondary orthodontic care. All patients that were referred for orthodontic treatment to the Orthodontic Unit of the University Dental Hospital of Manchester who lived in the inner city of Manchester and Tameside were eligible for this project.

The main hospital base was the orthodontic department of the University Dental Hospital of Manchester. This is a large orthodontic unit based within the Dental Directorate of Central Man- 
chester Health Care Trust. The outreach clinics were based in three of the possible sites:

- Moss Side Health Centre: This is a four chair dental department that is $500 \mathrm{~m}$ from the main base clinic.

- Longsight Health Centre: This is a five chair dental department that is $2 \mathrm{~km}$ from the main base.

- Hyde Health Centre: This is a one chair dental department that is $15 \mathrm{~km}$ from the main base.

These centres were chosen because they are situated in the main referral areas of the dental hospital. We also felt that because we were testing accessibility, the selection of three centres that were different distances from the main base was relevant.

\section{Assignment}

When a dentist referred a patient for a consultation appointment we carried out the following:

- Patients from the health centre catchment areas were identified using their postcode.

- They were then randomly allocated to receive a consultation in the main base hospital or in an outreach clinic at the local community health centre. This was done using previously prepared lists, prepared using random number tables, for each site area.

\section{Collection of data}

When the patients and their parents attended any of the clinics they were seen by either a consultant orthodontist (KO'B) or a senior registrar (RM) for an orthodontic new patient consultation. The clinicians recorded the following data:.

- The outcome of the consultation

- Need for treatment measured by Index for Orthodontic

Treatment Need (IOTN)

- The reason for the treatment decision

- Whether radiographs were taken

The referral was classified as being appropriate or inappropriate using the definition used in our previous investigations into orthodontic referrals. ${ }^{11}$

They also completed a study questionnaire that was administered by a research associate.

\section{The nature of the consultation}

The consultation appointment between the orthodontist and the patient was a triage appointment that was intended to identify whether orthodontic treatment was needed, if the patient was prepared to wear fixed appliances and whether the patient's oral health was adequate for orthodontic treatment. No attempt was made to formulate a definitive treatment plan. If the patient was accepted for treatment they were placed on the main base treatment waiting list, which at the time of the study was 12 months long.

\section{Outcome measures}

We used the following primary outcome measures:

- Whether the patient was accepted for orthodontic treatment

- The total time spent in the health centre or main base hospital, excluding additional time spent completing questionnaires.

- Patient attendance

\section{Consumer data}

We also collected data that measured the consumer's perceptions of the service. This was done using a questionnaire administered by a research assistant to the adult who was accompanying the patient.
The questionnaire included questions on:

- Travel arrangement and costs

- Preference for site of appointment

Satisfaction with the clinic was measured using the Group Health Association of America Consumer Satisfaction Survey. ${ }^{12}$ This measures satisfaction on a 5-point scale ranging from poor to excellent.

\section{Cost data}

The relative costs in the main base and the outreach clinics were determined. The yearly capital costs, overheads and equipment charges were initially calculated per square metre, and then scaled up by the area for each dental site. This, combined with the yearly throughput of outpatients, enabled a cost per patient to be determined, which should be comparable between the sites. The use of orthodontic and nursing staff was equivalent in each site, and all clerical work was done at the main base. Consequently these costs were not included in the comparison. The cost of the clinicians to travel to the outreach clinics from the main base was included.

\section{Sample size calculation}

We based the sample size calculation on potential differences in the proportion of patients who did not attend their appointments, using data derived from a previous investigation. ${ }^{11}$ For a study with a power of $90 \%$ and an alpha of 0.05 , we selected a meaningful difference in the proportion of patients who fail to attend their appointment of $15 \%$. We calculated that we needed a sample of 127 patients in each group (main base or outreach).

\section{Data analysis}

Any differences between the two groups were evaluated with the Student's ' $\mathrm{t}$ ' test or the Mann-Whitney U test depending upon the nature of the data. Any comparisons between proportions were evaluated with the chi-squared test.

\section{Masking}

The referred patients were aware that they were involved in a study, but they did not know that they could have received their consultation appointment in a different location. The clinicians were aware of the site of consultation. The data were entered onto a database. During this process none of the investigating team were aware of the group to which the patient had been randomised. The identifying code was broken only when the data had been analysed.

\section{Results}

\section{The patients in the study}

A total of 324 patients were entered into the study, 169 (52.2\%) were allocated to an outreach clinic and $155(47.8 \%)$ were given appointments in the main hospital base. Table 1 shows patient attendance. There was no difference in attendance between the hospital and the outreach clinics $\left(\chi^{2}=0.094, \mathrm{df}=2, P=0.95\right)$. When we evaluated the effect of socio-economic status on attendance we found that attenders had the lowest mean deprivation score (Townsend index obtained from the postcode), those who cancelled the appointment the next highest score, and those who failed to attend the appointment had the highest deprivation score (Table 2). Using ANOVA followed by the Bonferroni adjustment we found that there was a statistically significant difference between the deprivation scores for those who attended and those who failed to attend without notification $(P=0.030)$.

Table 3 contains data on the outcome of the consultation for both settings. Table 4 includes data on the classification of refer- 
Table I Patient attendance at the outreach and main base clinic

\begin{tabular}{lrcrrrr}
\hline Attendance & \multicolumn{2}{c}{ Outreach clinics } & \multicolumn{2}{c}{ Main base } & \multicolumn{2}{c}{ Total } \\
& No. & $(\%)$ & No. & $(\%)$ & No. & $(\%)$ \\
\hline Yes & & & & & & \\
Cancellation & 116 & $(68.6)$ & 108 & $(69.7)$ & 224 & $(69.1)$ \\
Non attender & 35 & $(10.7)$ & 17 & $(11.0)$ & 35 & $(10.8)$ \\
\hline Total & 169 & $(100.0)$ & 155 & $(100.0)$ & 324 & $(100.0)$ \\
\hline
\end{tabular}

Table 2 Analysis of attendance and levels of social deprivation of the patients

\begin{tabular}{|c|c|c|c|c|c|}
\hline \multirow[t]{2}{*}{ Attendance } & \multirow[t]{2}{*}{ Number } & \multirow[t]{2}{*}{$\begin{array}{l}\text { Mean } \\
\text { Townsend } \\
\text { score }\end{array}$} & \multirow[t]{2}{*}{$\begin{array}{l}\text { Standard } \\
\text { deviation }\end{array}$} & \multicolumn{2}{|c|}{$\begin{array}{l}95 \% \text { Confidence } \\
\text { interval for } \\
\text { the mean }\end{array}$} \\
\hline & & & & Lower & Upper \\
\hline Yes & 213 & 5.0 & 3.8 & 4.6 & 5.6 \\
\hline Cancelled & 31 & 5.9 & 3.5 & 4.7 & 7.2 \\
\hline Failed to attend & 60 & 6.4 & 3.7 & 5.5 & 7.4 \\
\hline Total & 304 & 5.4 & 3.8 & 5.0 & 5.9 \\
\hline \multicolumn{6}{|l|}{ Anova table } \\
\hline & $\begin{array}{l}\text { Sum of } \\
\text { squares }\end{array}$ & $d f$ & $\begin{array}{r}\text { Mean } \\
\text { squares }\end{array}$ & $\mathrm{F}$ & Sig \\
\hline $\begin{array}{l}\text { Between groups } \\
\text { Within groups }\end{array}$ & $\begin{array}{r}102.0 \\
4189.1\end{array}$ & $\begin{array}{r}2 \\
301\end{array}$ & $\begin{array}{l}51.0 \\
13.9\end{array}$ & 3.67 & 0.027 \\
\hline Total & 4291.I & 303 & & & \\
\hline
\end{tabular}

rals as appropriate or inappropriate. The proportion of suitable referrals seen in each setting was compared using the chi square test. There was no difference $\left(\chi^{2}\right.$ with continuity correction $=$ $1.09,1 \mathrm{df}, P=0.296)$.

The convenience of the clinic and cost incurred

by the patients

These data are included in Table 5. Analysis revealed that the distance travelled, the time taken and cost of travel were significantly lower for those attending the outreach clinic. When we considered the consumer's opinions more people attending the main base cited parking and cost as a problem.

Analysis of the duration of the appointment revealed that the total time in the health centre/main base from arrival was 28.1
Table 3 The outcome of consultation

\begin{tabular}{lrrrrrr}
\hline Outcome & \multicolumn{2}{c}{ Overall } & \multicolumn{3}{c}{ Outreach } & \multicolumn{2}{c}{ Main base } \\
& No. & $(\%)$ & No. & $(\%)$ & No. & $(\%)$ \\
\hline & & & & & & \\
Treatment offered & 79 & $(35.4)$ & 42 & $(36.5)$ & 37 & $(34.3)$ \\
Referred to specialist & 11 & $(4.9)$ & 6 & $(5.2)$ & 5 & $(4.6)$ \\
Referred to another & 20 & $(9.0)$ & 12 & $(10.5)$ & 8 & $(7.3)$ \\
Hospital department & & & & & & \\
Referred to GDP & 17 & $(7.7)$ & 6 & $(5.2)$ & 11 & $(10.2)$ \\
Declined & 11 & $(4.9)$ & 6 & $(5.2)$ & 5 & $(4.6)$ \\
Undecided & 7 & $(3.1)$ & 6 & $(5.2)$ & 1 & $(0.9)$ \\
Poor oral condition & 31 & $(14.0)$ & 12 & $(10.5)$ & 19 & $(17.5)$ \\
Review appointment & 4 & $(1.8)$ & 0 & $(0.0)$ & 4 & $(3.8)$ \\
No treatment required & 23 & $(10.3)$ & 13 & $(11.3)$ & 10 & $(9.3)$ \\
Too early & 17 & $(7.6)$ & 9 & $(7.8)$ & 8 & $(7.4)$ \\
Referred for x-ray & 3 & $(1.3)$ & 3 & $(2.6)$ & 0 & $(0.0)$ \\
\hline Total & 223 & $(100.0)$ & 115 & $(100.0)$ & 108 & $(100.0)$
\end{tabular}

Table 4 Classification of appropriateness of referral

\begin{tabular}{lcccccrr}
\hline & \multicolumn{2}{c}{ Main base } & \multicolumn{2}{c}{ Outreach } & \multicolumn{2}{c}{ Total } \\
\hline & No. & $(\%)$ & No. & $(\%)$ & No. & $(\%)$ \\
\hline Suitable referral & 67 & $(62.0)$ & 80 & $(69.6)$ & 147 & $(65.9)$ \\
Unsuitable referral & 41 & $(38.0)$ & 35 & $(30.4)$ & 76 & $(34.1)$ \\
\hline Total & 108 & $(100.0)$ & 115 & $(100.0)$ & 223 & $(100.0)$ \\
\hline
\end{tabular}

minutes $(\mathrm{sd}=13.3)$ for the outreach clinic and for the main base it was 42.1 minutes $(\mathrm{sd}=26.6) \quad$ (Mann-Whitney U-test; $P<0.002)$. Similarly, the time in the clinic from the actual appointment was 20.5 minutes $(s d=19.6)$ for the outreach clinic and 31.7 minutes $(\mathrm{sd}=26.3)$ for the main base (Mann Whitney U-test; $P<0.002$ ).

\section{Patient's views}

Table 6 includes data on the consumer's satisfaction with the visit and preferences for location of consultation. Consumers who attended the outreach clinic were more satisfied than those who attended the main base clinic with the location of the clinic. However, those who attended the main base hospital were more satisfied with the surroundings and waiting room facilities.

When we considered their preferences for the location of the consultation we found that $62(57.4 \%)$ of the outreach and 50 $(49 \%)$ of the main base patients preferred to attend a clinic near home. However, 97 (92.4\%) of the outreach and 76 (97.4\%) of the main base patients would have been prepared to see the orthodontist in another setting (Table 7).

Table 5 The cost and convenience of the clinic to patients

\begin{tabular}{|c|c|c|c|c|c|c|c|}
\hline & \multicolumn{2}{|c|}{ Overall } & \multicolumn{2}{|c|}{ Outreach } & \multicolumn{2}{|c|}{ Main base } & \multirow[t]{2}{*}{$P$} \\
\hline & Mean & sd & Mean & sd & Mean & sd & \\
\hline $\begin{array}{l}\text { Was cost a problem? Yes } \\
\text { Was it easy to park? Yes }{ }^{\dagger}\end{array}$ & $\begin{array}{l}31 \\
79\end{array}$ & $\begin{array}{l}(15.0) \\
(56.8)\end{array}$ & $\begin{array}{r}8 \\
62\end{array}$ & $\begin{array}{r}(7.5) \\
(84.7)\end{array}$ & $\begin{array}{l}23 \\
18\end{array}$ & $\begin{array}{l}(23.2) \\
(26.9)\end{array}$ & $\begin{aligned} & 0.001 \\
< & 0.0005\end{aligned}$ \\
\hline
\end{tabular}

* Cost calculated at I 3 p per mile (AA marginal cost) or actual cost of public transport used

t Percentage given of those arriving by car who answered the question 
Table 6 Patient perceptions of their visit *

\begin{tabular}{|c|c|c|c|c|}
\hline & & $\begin{array}{l}\text { Outreach } \\
\text { clinic }\end{array}$ & $\begin{array}{l}\text { Main } \\
\text { base }\end{array}$ & $\begin{array}{l}\text { Significance } \\
\text { (2 tailed from } \\
\text { Mann-Whitney } \\
\text { test) }\end{array}$ \\
\hline $\begin{array}{l}\text { Convenience of } \\
\text { location of } \\
\text { the clinic }\end{array}$ & $\begin{array}{l}\text { Median } \\
\text { interquartile } \\
\text { range }\end{array}$ & $\begin{array}{l}3.0 \\
3.0-4.0\end{array}$ & $\begin{array}{l}2.0 \\
2.0-3.0\end{array}$ & 0.002 \\
\hline $\begin{array}{l}\text { Quality of waiting } \\
\text { areas and } \\
\text { facilities }\end{array}$ & $\begin{array}{l}\text { Median } \\
\text { interquartile } \\
\text { range }\end{array}$ & $\begin{array}{l}3.0 \\
3.0-3.0\end{array}$ & $\begin{array}{l}3.0 \\
3.0-4.0\end{array}$ & $<0.0005$ \\
\hline
\end{tabular}

* Responses on a scale from I = poor to $5=$ excellent

Table 7 Patient preferences according to the site of the consultation

\begin{tabular}{llrlr}
\hline & \multicolumn{2}{c}{ Outreach } & \multicolumn{2}{c}{ Main base } \\
& No. & $(\%)$ & No. & $(\%)$ \\
\hline $\begin{array}{l}\text { Prefer hospital } \\
\text { Prefer clinic nearby }\end{array}$ & 10 & $(9.3)$ & 20 & $(19.6)$ \\
No preference & 62 & $(57.4)$ & 50 & $(49.0)$ \\
\hline $\begin{array}{l}\text { Willing to see } \\
\text { orthodontist at } \\
\text { the alternative site }\end{array}$ & 97 & $(33.3)$ & 32 & $(31.4)$ \\
\hline
\end{tabular}

The costs of the outreach clinic compared with the main base clinics

The per patient costs were very similar and are shown in Table 8.

\section{Discussion}

This investigation revealed that the only benefits of seeing orthodontic patients in outreach clinics were a reduction in their time at the clinic and a small reduction in travel costs. When we considered consumer preferences, it appeared that most people, when they expressed a preference, preferred to have a consultation at an outreach clinic. However, one third did not express a preference and nearly all the consumers were willing to see an orthodontist in another setting. This is in agreement with a meta-analysis of the literature on patient's satisfaction with medical care and the investigation into specialist outreach clinics for dermatology and orthopaedics and investigations into dermatology and orthopaedic outreach clinics. ${ }^{6}$

Evaluation of the patient attendance patterns and outcome of the consultation revealed that there were no differences between the two types of setting. Furthermore, the outcome of the consultation was not markedly different from that recorded in a previous investigation. ${ }^{10}$ This suggests that providing consultation appointments in an outreach clinic does not influence the decisions of the orthodontists.

It was also relevant to consider the patient attendance pattern. We found that this was associated with social deprivation score. While in this investigation this did not result in any differences between the two settings of consultation there may be an effect if outreach clinics are set up in community health centres. These are mostly sited in areas of deprivation. As a result, all patients who are living near the clinics may be seen in the outreach. Patients who live in less deprived areas, where there are fewer community health centres, may be given appointments in the main hospital base. This could result in the populations of patients being different, resulting in different attendance patterns.

It was also important to find that few patients needed onward referral to the main base for specialised radiographs. However, this may be a result of the nature of the consultation where the first appointment is a 'filter' for secondary care. The patient's treatment is then planned in detail when they are taken off a treatment waiting list.

\section{Conclusion}

The results of this investigation reveal that there are few advantages or disadvantages to providing orthodontic consultation appointments in an outreach setting. Most of the advantages are perceived from the patient's point of view, in that they expressed a preference to be seen nearer home. When we consider the orthodontist's point of view, there are implications of moving consultants out of the hospital base. In this study, the opportunity cost of the consultant's absence from the hospital base amounted to only a small proportion of the working week. However, if this was extended and they spent more time in outreach clinics, this would result in a lack of availability to provide advice and training and, perhaps, lead to a decline in the quality of care.

Another factor that also needs consideration is the organisation required for an outreach scheme. We used three community health centres and it did take some time to set up the outreach mechanism. However, once this was done, the workload was no different from that needed for a main base clinic. Nevertheless, it was necessary to place patients on a waiting list for each outreach clinic, so that each session was fully booked. Paradoxically, this resulted in some patients having to wait in excess of the 13 weeks Patients Charter recommendation and we received criticism from our hospital administration, even though the patients were being seen in an effective manner.

\section{Limitations of this study}

This study may be limited because of the use of community health centres as outreach clinics. Consideration could be given to patients being seen in general dental practices and this would have the considerable advantage of the consultant seeing the patients with the dentists. Unfortunately, this may not be possible because it is unlikely that even a large dental practice would generate enough referrals to make a regular outreach clinic effective and there may be a reticence for dentists to refer patients for a consultation taking place in the practice of another general practitioner.

It could also be suggested that the findings in this investigation are only relevant to the provision of orthodontic consultations in large conurbations. Our conclusions may not be totally transferable to the rural setting, where the distances to travel

Table 8 The cost of treatment in each setting

\begin{tabular}{|c|c|c|c|c|c|}
\hline & $\begin{array}{c}\text { Capital } \\
\text { cost/square } \\
\text { metre/year } \\
£\end{array}$ & $\begin{array}{c}\text { Equipment/ } \\
\text { square } \\
\text { metre/year } \\
£\end{array}$ & $\begin{array}{c}\text { Overheads/ } \\
\text { square } \\
\text { metre/year } \\
£\end{array}$ & Cost/patient & $\begin{array}{c}\text { Cost/patient } \\
\text { including travel and } \\
\text { opportunity costs } \\
\qquad\end{array}$ \\
\hline Main base & 79.56 & 12.26 & 160.14 & 7.13 & 9.11 \\
\hline Outreach clinics & 104.14 & 50.51 & 86.55 & 6.36 & $8.40 *$ \\
\hline
\end{tabular}

*Including mileage at 13 per mile and opportunity cost calculated using

Dental Guild rate of $£ \mid 87.50$ per session 
may be greater and public transport systems not as well developed as in city areas.

Nevertheless, this study must be considered to have generality and provides useful information for those wishing to set up outreach clinics. Further research is needed on the long-term benefits of outreach, perhaps using large general dental practices as outreach clinics along with an evaluation of the effectiveness of outreach care in rural areas.

\section{Conclusions}

From this study we can conclude that in general there were no marked advantages or disadvantages of orthodontic consultation outreach clinics in terms of cost or outcome of care.

The authors would like to acknowledge the Central Manchester Healthcare Trust Research Committee for funding this project.

1 Bailey J, Black M, Wilkin D. Specialist outreach clinics in general practice. Br Med J 1994; 308: 1083-1086.

2 Association of community health councils. Fundholding and access to hospital care. Health News briefing. March 1994.
3 Audit Commission. What the Doctor ordered: a study of GP fundholders in England and Wales. London: HMSO, 1996.

4 Mitchell AR. Psychiatrists in primary health care settings. Br J Psych 1985; 147: 371-379.

5 Gillam et al. Investigation of the benefits and costs of an opthalmic outreach clinic in general practice. Br J Gen Prac 1995; 45: 649-652.

6 Black M, Leese B, Gosden T, Mead N. Specialist outreach clinics in general practice; What do they offer? Br J Gen Prac 1997; 47: 558-561.

7 Gosden T, Black M, Mead N, Leese B. The efficiency of specialist outreach clinics in general practice: Is further evaluation needed? J Health Services Res Pol 1997; 2: 174-179.

8 Bowling A, Stramer K, Dickinson E et al. Evaluation of specialists' outreach clinics in general practice in England; process and acceptability to patients, specialists and general practitioners. J Epidemiol Comm Health 1997; 51: 52-61.

9 O'Brien KD et al. Dentist's perceptions of orthodontic services. Br Dent J 1995; 178: 461-464.

10 O'Brien K D et al. Do dentists refer patients inappropriately. Br Dent J 1996: 181; 132-136.

11 O'Brien K D, Wright J, Conboy F et al. The effect of orthodontic referral guidelines: A randomised controlled trial. Br Dent J2000; 188: 392-397.

12 Davies A R, Ware J E. GHAA's consumer satisfaction survey and manual. Washington: Group Health Association of America, 1991. 